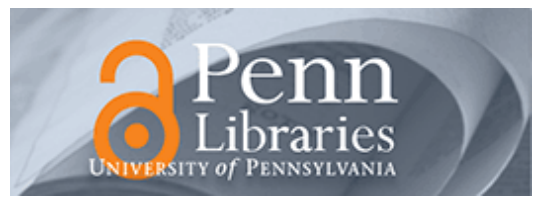

University of Pennsylvania ScholarlyCommons

$5-15-2012$

\title{
Rho Kinase Signaling Pathways During Stretch in Primary Alveolar Epithelia
}

Brian Christopher DiPaolo

University of Pennsylvania, bdipaolo@seas.upenn.edu

Susan S. Margulies

University of Pennsylvania, margulies@seas.upenn.edu

Follow this and additional works at: https://repository.upenn.edu/be_papers

Part of the Biomedical Engineering and Bioengineering Commons, and the Cellular and Molecular Physiology Commons

\section{Recommended Citation}

DiPaolo, B. C., \& Margulies, S. S. (2012). Rho Kinase Signaling Pathways During Stretch in Primary Alveolar Epithelia. American Journal of Physiology - Molecular Physiology, 302 (10), L992-L1002. http://dx.doi.org/10.1152/ajplung.00175.2011 


\title{
Rho Kinase Signaling Pathways During Stretch in Primary Alveolar Epithelia
}

\begin{abstract}
Alveolar epithelial cells (AECs) maintain integrity of the blood-gas barrier with actin-anchored intercellular tight junctions. Stretched type I-like AECs undergo magnitude- and frequency-dependent actin cytoskeletal remodeling into perijunctional actin rings. On the basis of published studies in human pulmonary artery endothelial cells (HPAECs), we hypothesize that RhoA activity, Rho kinase (ROCK) activity, and phosphorylation of myosin light chain II (MLC2) increase in stretched type l-like AECs in a manner that is dependent on stretch magnitude, and that RhoA, ROCK, or MLC2 activity inhibition will attenuate stretch-induced actin remodeling and preserve barrier properties. Primary type I-like AEC monolayers were stretched biaxially to create a change in surface area $(\triangle S A)$ of $12 \%, 25 \%$, or $37 \%$ in a cyclic manner at $0.25 \mathrm{~Hz}$ for up to $60 \mathrm{~min}$ or left unstretched. Type I-like AECs were also treated with Rho pathway inhibitors (ML-7, Y-27632, or blebbistatin) and stained for F-actin or treated with the myosin phosphatase inhibitor calyculin-A and quantified for monolayer permeability. Counter to our hypothesis, ROCK activity and MLC2 phosphorylation decreased in type l-like AECs stretched to $25 \%$ and $37 \% \triangle$ SA and did not change in monolayers stretched to $12 \% \triangle$ SA. Furthermore, RhoA activity decreased in type Ilike AECs stretched to $37 \% \triangle$ SA. In contrast, MLC2 phosphorylation in HPAECs increased when HPAECs were stretched to $12 \% \triangle \mathrm{SA}$ but then decreased when they were stretched to $37 \% \triangle \mathrm{SA}$, similar to type I-like AECs. Perijunctional actin rings were observed in unstretched type I-like AECs treated with the Rho pathway inhibitor blebbistatin. Myosin phosphatase inhibition increased MLC2 phosphorylation in stretched type l-like AECs but had no effect on monolayer permeability. In summary, stretch alters RhoA activity, ROCK activity, and MLC2 phosphorylation in a manner dependent on stretch magnitude and cell type.
\end{abstract}

\section{Keywords}

RhoA, myosin regulatory light chain, perijunctional actomyosin ring, epithelial, lung injury, mechanical ventilation

Disciplines

Biomedical Engineering and Bioengineering | Cellular and Molecular Physiology | Engineering 


\title{
Rho kinase signaling pathways during stretch in primary alveolar epithelia
}

\author{
Brian C. DiPaolo and Susan S. Margulies
}

\section{Abstract}

Alveolar epithelial cells (AECs) maintain integrity of the blood-gas barrier with actin-anchored intercellular tight junctions. Stretched type I-like AECs undergo magnitude- and frequency-dependent actin cytoskeletal remodeling into perijunctional actin rings. On the basis of published studies in human pulmonary artery endothelial cells (HPAECs), we hypothesize that RhoA activity, Rho kinase (ROCK) activity, and phosphorylation of myosin light chain II (MLC2) increase in stretched type I-like AECs in a manner that is dependent on stretch magnitude, and that RhoA, ROCK, or MLC2 activity inhibition will attenuate stretch-induced actin remodeling and preserve barrier properties. Primary type I-like AEC monolayers were stretched biaxially to create a change in surface area $(\Delta \mathrm{SA})$ of $12 \%, 25 \%$, or $37 \%$ in a cyclic manner at $0.25 \mathrm{~Hz}$ for up to $60 \mathrm{~min}$ or left unstretched. Type I-like AECs were also treated with Rho pathway inhibitors (ML-7, Y-27632, or blebbistatin) and stained for F-actin or treated with the myosin phosphatase inhibitor calyculin-A and quantified for monolayer permeability. Counter to our hypothesis, ROCK activity and MLC2 phosphorylation decreased in type I-like AECs stretched to $25 \%$ and $37 \% \Delta \mathrm{SA}$ and did not change in monolayers stretched to $12 \% \triangle \mathrm{SA}$. Furthermore, RhoA activity decreased in type I-like AECs stretched to $37 \% \triangle \mathrm{SA}$. In contrast, MLC2 phosphorylation in HPAECs increased when HPAECs were stretched to $12 \%$ $\triangle \mathrm{SA}$ but then decreased when they were stretched to $37 \% \triangle \mathrm{SA}$, similar to type I-like AECs. Perijunctional actin rings were observed in unstretched type I-like AECs treated with the Rho pathway inhibitor blebbistatin. Myosin phosphatase inhibition increased MLC2 phosphorylation in stretched type I-like AECs but had no effect on monolayer permeability. In summary, stretch alters RhoA activity, ROCK activity, and MLC2 phosphorylation in a manner dependent on stretch magnitude and cell type.

Keywords: RhoA, myosin regulatory light chain, perijunctional actomyosin ring, epithelial, lung injury, mechanical ventilation MECHANICAL VENTILATION is a critical intervention for particular life-threatening conditions but has been implicated in pulmonary injury because of the delivery of large gas volumes to localized lung regions, high-magnitude basement membrane (86) and pulmonary alveolar epithelial cell (AEC) biaxial stretch, and increased blood-gas barrier permeability $(33,48)$. Cultured rat AEC monolayers with type I features used to mimic the alveolar epithelium in vitro $(12,19,27,55,67)$ have been shown to exhibit perijunctional F-actin rings (PJARs) and to increase monolayer permeability in response to high-magnitude biaxial stretch levels, which are analogous to pathological ventilator volumes $(17,29)$. However, little is known about the underlying mechanistic pathways involved in PJAR rearrangement and the influence of PJAR rearrangement on monolayer permeability in type I AECs.

The actin cytoskeleton is a mechanosensitive load-bearing structure in the cell that assists in cell-cell adhesion $(3,14,15,21,29)$, and anchors tight junction (TJ) proteins $(34,58)$. The PJAR, which some refer to as the perijunctional actomyosin ring (87), is a specific morphological conformation of F-actin formed rapidly in biaxially stretched rat type I-like AECs (29) and endothelial cells (91), and has been shown to contain the contractile protein myosin in endothelial cells $(7,93)$. However, it is not yet understood if myosin contracts to rearrange into PJARs in response to stretch and if this contraction would provide enough force to increase the TJ-mediated paracellular permeability found previously $(16,17)$. Mechanistic pathways responsible for stretch-induced actin rearrangement into PJARs are also poorly understood in type I-like AECs.

Myosin II has been shown to cross-link with filamentous actin directly, and numerous actin-binding proteins $(36,46)$ contribute to PJAR structure (93) and change its conformation (32) and activity based on mechanical stretch pathways in other cell types (8, 75, 90). It is not yet understood how significantly myosin II interacts in PJAR contraction and TJ-mediated paracellular permeability during stretch. PJAR contraction has been shown to have a causal relationship with Rho-mediated phosphorylation of myosin light chain II (MLC2) in various cell types $(11,79)$. Nonmuscle myosin II is activated through the Rho pathway and provides contractile force via phosphorylation of MLC2 at $\operatorname{Thr}^{18}$ and $\operatorname{Ser}^{19}(38,40,60,74)$, with force generation greater with phosphorylation at both residues than with monophosphorylation (61). MLC2 can be inhibited with phosphorylation at $\operatorname{Ser}^{1}$ and $\operatorname{Ser}^{2}(38,41,60,74)$, resulting in reduced myosin affinity for actin filaments.

MLC2 can be pharmacologically inhibited with blebbistatin (96), an inhibitor of myosin II ATPase. Active (GTP-bound) Rho activates Rho kinase (ROCK) (43). ROCK phosphorylates the myosin binding subunit of myosin phosphatase (MP), inhibiting its activity and, thus, increasing phosphorylation of MLC2 of myosin II $(22,49,72,83)$ and its contractile force (61). Additionally, ROCK directly 
phosphorylates MLC2 at $\operatorname{Thr}^{18}$ and $\operatorname{Ser}^{19}$ (2), with a higher affinity for $\operatorname{Ser}^{19}$ (40, 83), promoting actin filament assembly (20, 26). ROCK can be inhibited by Y-27632 $(35,69,94)$ and has been shown to result in decreased MLC2 phosphorylation (5). MP can be inhibited by calyculin-A $(23,42)$ and has been shown to increase MLC2 phosphorylation (5). Myosin light chain kinase (MLCK) has also been found to phosphorylate MLC2 (45) at $\operatorname{Thr}^{18}$ and $\operatorname{Ser}^{19}$ (2). MLCK is activated by ERK (50) and can be inhibited by ML-7, a membranepermeable agent (52). ROCK-mediated MLC2 phosphorylation has been shown to be confined to cell central areas, while MLCKmediated MLC2 phosphorylation has been shown to localize at cell peripheral locations in fibroblasts (83). Finally, numerous other signaling proteins may contribute to Rho pathway regulation during stretch $(56,66,80)$. We hypothesize that type I-like AECs will activate the Rho pathway during stretch. We also hypothesize an increase in RhoA and ROCK activity, phosphorylation of MLC2, and rearrangement into PJARs. We further hypothesize that inhibition of these pathways will inhibit rearrangement into PJARs and attenuate the stretch-induced increase in monolayer permeability.

Others have shown activation of the Rho pathway and have characterized its influence on the actin cytoskeleton (1, 8-10, 47, 51, 77), TJ protein, and monolayer permeability properties in stretched endothelial cells and other cell types $(8,25,65,68,75,88,90)$. Furthermore, others have implicated the Rho pathway and its effect on actin structure, TJ protein distribution, and TJ-mediated paracellular permeability in unstretched epithelial cells $(13,39,59,64,76,78,88-90)$. However, there is a paucity of studies investigating these pathways and relationships in stretched pulmonary alveolar cells. We investigated the MLCK, ROCK, and MLC2 pathways and their effect on cytoskeletal rearrangement into PJARs in type I-like AECs.

The goals of the present study are to test whether stretch-induced PJAR rearrangement is dependent on the ROCK- and MLC2-mediated pathway. Our overall hypothesis is that rapid cytoskeletal remodeling and rearrangement into PJARs are activated by ROCK accompanied downstream by MLC2 activation. We tested functional relationships by inhibiting this pathway and expected that it would inhibit PJAR rearrangement.

\section{MATERIALS AND METHODS}

Primary rat type I-like AEC isolation. Alveolar type II cells were isolated from male Sprague-Dawley rats (190-300 g) based on a method reported by Dobbs et al. (31) with slight modification $(29,86)$. The animal protocols were reviewed and approved by the University of Pennsylvania Institutional Animal Care and Use Committee. Cells were seeded at $1.0 \times 10^{6} \mathrm{cells} / \mathrm{cm}^{2}$ onto fibronectin-coated $\left(10 \mu \mathrm{g} / \mathrm{cm}^{2}\right.$; Invitrogen) flexible Silastic membranes (Specialty Manufacturing, Saginaw, MI) in custom-designed wells (85). The cells were cultured for 4 days at $37^{\circ} \mathrm{C}$ in $5 \% \mathrm{CO}_{2}$ in MEM $+\mathrm{FBS}$, which was replaced daily. After 4 days, the cells had adopted alveolar type I features (12, 19, 24, 27, 67, 70), including the expression of RTI40, and had grown to a confluent monolayer. Monolayers were then serum-deprived in DMEM (Mediatech, Manassas, VA) supplemented with $20 \mathrm{mM}$ HEPES (Sigma) for $3 \mathrm{~h}$ and stretched biaxially across a range of physiologically relevant magnitudes, including $12 \%, 25 \%$, or $37 \%$ change in surface area $(\triangle \mathrm{SA})$, roughly corresponding to $64 \%$, $86 \%$, and $100 \%$ total lung capacity, respectively (85).

Human pulmonary artery endothelial cell culture. Human pulmonary artery endothelial cells (HPAECs, passages 8-10; provided by Dr. Christopher Chen, University of Pennsylvania) were seeded at $0.163 \times 10^{6}$ cells $/ \mathrm{cm}^{2}$ onto collagen I-coated $\left(5 \mu \mathrm{g} / \mathrm{cm}^{2}\right.$ overnight; BD Biosciences, San Jose, CA) flexible Silastic membranes in custom-designed wells (85), similar to a culture method described elsewhere (8). The cells were cultured for $48 \mathrm{~h}$ at $37^{\circ} \mathrm{C}$ in $5 \% \mathrm{CO}_{2}$ in epithelial basal medium (EBM-2, Lonza, Basel, Switzerland) supplemented with epithelial growth medium (hydrocortisone, hEGF, VEGF, hFGF-B, R3-IGF-I, ascorbic acid, heparin, and gentamicin-amphotericin B; EGM-2, Lonza), 10\% FBS, 1\% L-glutamine, and 1\% 1:1 penicillin-streptomycin.

Western blot measurement of MLC2 phosphorylation. Cells were lysed and protein content was quantified by a method similar to that described elsewhere $(5,8,69)$. Serum-deprived monolayers were stretched biaxially to $12 \%, 25 \%$, or $37 \% \Delta$ SA cyclically at $0.25 \mathrm{~Hz}$ for 0 (unstretched), 1, 10, 30, or $60 \mathrm{~min}$. A second group of monolayers were pretreated with the MP inhibitor calyculin-A (Cell Signaling Technology, Beverly, MA) at $10 \mathrm{nM}$ for $60 \mathrm{~min}$ or with DMSO as vehicle control and then stretched biaxially to $25 \% \Delta \mathrm{SA}$ cyclically at $0.25 \mathrm{~Hz}$ for 0 (unstretched) or $10 \mathrm{~min}$. A third group of HPAEC monolayers (with serum) were stretched to $12 \%, 25 \%$, or $37 \% \Delta \mathrm{SA}$ cyclically at $0.25 \mathrm{~Hz}$ for 0 (unstretched) or $30 \mathrm{~min}$.

Monolayers (3 wells/lysate) were washed twice with ice-cold Dulbecco's PBS (DPBS), lysed, and resolved by SDS-PAGE and immunoblot, as described previously (8). Membranes were incubated overnight with one of the following primary antibodies: anti-MLC2, anti-phosphorylated $\left(\mathrm{Ser}^{19}\right) \mathrm{MLC} 2$, or anti-phosphorylated $\left(\mathrm{Thr}^{18} / \mathrm{Ser}^{19}\right.$ ) MLC2 (all from Cell Signaling Technology) or antiphosphorylated $\left(\mathrm{Ser}^{1}\right)$ myosin light chain (ECM Biosciences, Versailles, KY). Membranes were then incubated with horseradish 
peroxidase (HRP)-conjugated secondary antibody (Santa Cruz Biotechnology, Santa Cruz, CA).

Immunoreactive proteins were detected with enhanced chemiluminescence (ECL Plus, GE Healthcare Biosciences, Piscataway, NJ). The relative density of the protein in the bands was quantified by scanning densitometry in ImageJ (version 1.43j) based on optimization described by Gassmann et al. (37). Background intensity for each lane was subtracted from blot intensity. Protein density was normalized by the unstretched-untreated density. Membranes were reprobed with the relevant total protein antibody or with anti-GAPDH (Millipore, Billerica, MA) to ensure equivalent protein loading (30).

Normalized density of the phosphorylated protein was divided by normalized density of the respective total protein or GAPDH signal and reported. To test the effect of stretch, animal average normalized density values ( $\geq 3$ animals/group) were compared with time-matched unstretched controls using a two-way ANOVA with post hoc Dunnett's test (95) in JMP (version 8.0, SAS Institute, Cary, NC). To test the effect of treatment, animal average normalized density values ( $\geq 3$ animals/group) were compared with time-matched vehicle controls as well as unstretched-untreated controls using a two-way ANOVA with Tukey-Kramer post hoc analysis (95) in JMP.

RhoA activity assay. Endogenous RhoA activity was quantified using an in vitro colorimetric G-LISA kit (catalog no. BK124, Cytoskeleton, Denver, CO) according to the manufacturer's protocol. Serum-deprived monolayers were stretched biaxially to $37 \% \Delta \mathrm{SA}$ cyclically at $0.25 \mathrm{~Hz}$ for 0 (unstretched), 10, or $60 \mathrm{~min}$, washed twice with ice-cold DPBS, and then lysed and loaded equivalently (20 $\mu \mathrm{g})$ into a 96well plate. Active (GTP-bound) RhoA in each lysate was captured with immobilized rhotekin Rho binding domain, while inactive RhoA was not bound and was washed away. The wells were then immunostained with RhoA antibody and HRP-conjugated secondary antibody. The optical density of the HRP reaction was quantified at $490 \mathrm{~nm}$ on a microplate reader (model ELx800, BioTek, Winooski, VT). Background optical density was subtracted from each experimental optical density measurement.

The optical density of each experimental sample ( 2 replicates/sample, 2 samples/animal, $\geq 5$ animals/group) was divided by the respective optical density for the control (unstimulated-untreated) sample to calculate the normalized RhoA activity level. To test the effect of stretch, animal average normalized RhoA activity values were compared with time-matched unstretched controls using a one-way ANOVA with post hoc Dunnett's test (95) in JMP.

ROCK activity assay. Endogenous ROCK activity was quantified using an in vitro kinase assay (Cell Biolabs, San Diego, CA) with recombinant MP target subunit 1 as substrate, similar to the method described elsewhere $(6,54)$. Serum-deprived monolayers were stretched biaxially to $12 \%, 25 \%$, or $37 \% \Delta \mathrm{SA}$ cyclically at $0.25 \mathrm{~Hz}$ for 0 (unstretched), 10 , or $60 \mathrm{~min}$.

Monolayers (3 wells/lysate) were washed twice with ice-cold DPBS, scraped in radioimmunoprecipitation assay buffer with $5 \mathrm{mM}$ EDTA, $2 \mu \mathrm{g} / \mathrm{ml}$ pepstatin, $2 \mathrm{mM}$ sodium fluoride, $2 \mathrm{mM}$ sodium orthovanadate, and protease inhibitor cocktail (Complete Mini, Roche, Indianapolis, IN), sonicated, and then loaded into the kinase assay equivalently.

After resolving by SDS-PAGE and immunoblot, membranes were probed with anti-phosphorylated (Thr ${ }^{696}$ ) MP target subunit 1 to determine sample recombinant MP target subunit 1 phosphorylation by ROCK (ROCK activity) and with GAPDH to normalize the signal to sample total protein (30). Protein density was normalized by the unstretched-untreated density. Normalized density of phosphorylated MP target subunit 1 was divided by normalized density of the GAPDH signal and reported.

MLC2 immunofluorescence and F-actin staining. Monolayers were pretreated with the myosin II ATPase activity inhibitor blebbistatin, MLCK inhibitor ML-7, or ROCK inhibitor Y-27632 (all $10 \mu \mathrm{M}$ for $60 \mathrm{~min}$; EMD Chemicals, Gibbstown, NJ) or with DMSO as vehicle control and then stretched biaxially to $37 \% \Delta \mathrm{SA}$ cyclically at $0.25 \mathrm{~Hz}$ for 0 (unstretched) or $60 \mathrm{~min}$ and stained for F-actin (phalloidin; Invitrogen, Carlsbad, CA), G-actin (DNase I; Invitrogen), and double-stranded DNA (4',6-diamidino-2-phenylindole; Invitrogen). An additional group of monolayers were stretched to $37 \% \Delta \mathrm{SA}$ at $0.25 \mathrm{~Hz}$ for 0 or $60 \mathrm{~min}$ and immunostained for MLC2 using anti-MLC2 or anti-phosphorylated $\left(\mathrm{Thr}^{18} / \mathrm{Ser}^{19}\right.$ ) MLC2 (Cell Signaling Technology). Monolayers were mounted on slides, and images were captured with an epifluorescence microscope (Eclipse TE300, Nikon, Melville, NY) with a $\times 40$ objective with constant intensity settings. Inhibitor concentration and treatment time were chosen on the basis of previously published studies and an initial dose-response experiment. Each inhibitor was also tested at 5 and $50 \mu \mathrm{M}$, along with incubation times of $30 \mathrm{~min}$ and $2 \mathrm{~h}$, with equivalent results shown here.

F- and G-actin content quantification. The F- and G-actin content in rat type I-like AEC monolayers was quantified using an in vivo assay (catalog no. BK037, Cytoskeleton) according to the manufacturer's protocol. Briefly, monolayers were pretreated with the myosin II ATPase activity inhibitor blebbistatin or ROCK inhibitor Y-27632 (both $10 \mu \mathrm{M}$ for $60 \mathrm{~min}$ ) or with DMSO as vehicle control and then stretched biaxially to $37 \% \Delta \mathrm{SA}$ cyclically at $0.25 \mathrm{~Hz}$ for 0 (unstretched) or $10 \mathrm{~min}$. Monolayers were then lysed into F-actin stabilization buffer, homogenized, and centrifuged at $100,000 \mathrm{~g}$ for $60 \mathrm{~min}$, all at $37^{\circ} \mathrm{C}$, and then separated into supernatant (G-actin) and pellet (F- 
actin, resuspended in $10 \mu \mathrm{M}$ cytochalasin D). The fractions were loaded equivalently (43.5 $\mu \mathrm{g})$ into a gel, resolved for SDS-PAGE and immunoblot, and probed with anti-G-actin. Membranes were incubated with HRP-conjugated secondary antibody, and the relative density of the protein in the bands was quantified by scanning densitometry in ImageJ (version 1.43j) based on optimization described elsewhere (37). Background intensity for each lane was subtracted from blot intensity. Protein density was normalized by the unstretched-vehicle control density.

Monolayer permeability. Others have shown that larger-sized molecules were able to cross the epithelium of whole lungs that had been inflated statically to high volumes $(33,48)$. More recently, the use of a custom-altered deformable porous copolyester membrane permitted the measurement of paracellular transport of different-sized tracers across stretched monolayers (16), although this membrane is severely limited in availability. Because of the lack of a deformable-permeable monolayer substrate, there is a paucity of data measuring intercellular tracer transport and transepithelial resistance (TER) between the apical and basal surface of a cyclically stretched cultured monolayer. Thus paracellular permeability was assessed by monitoring the flux of the fluorescent tracer BODIPYouabain across the monolayer, a novel method that can be carried out on our standard flexible Silastic nonpermeable membranes, as previously described (17). Using this method, Cavanaugh et al. (17) showed that the BODIPY-ouabain tracer was not internalized by cells, did not undergo receptor-mediated endocytosis, did not bind due to plasma membrane rupture, and did not bind nonspecifically; thus they hypothesized that it was transported across the epithelial monolayer via a paracellular, not a transcellular, route. Briefly, the apical surface of the monolayer was bathed in DMEM + HEPES containing $2 \mu \mathrm{M}$ BODIPY-ouabain (radius 20 $\AA$; Invitrogen), a fluorescent tracer that has a high affinity for the extracellular domain of the transmembrane $\mathrm{Na}^{+}-\mathrm{K}^{+}$-ATPase $(44,82)$ found on the basolateral surface of type I-like AECs (92), for 60 min during stretch (or for $60 \mathrm{~min}$ on unstretched monolayers). Monolayers were pretreated with the MP inhibitor calyculin-A (Cell Signaling Technology) at $10 \mathrm{nM}$ for $10 \mathrm{~min}$ or with DMSO as vehicle control and then stretched biaxially to $25 \% \Delta \mathrm{SA}$ cyclically at $0.25 \mathrm{~Hz}$ for 0 (unstretched), 10 , or $60 \mathrm{~min}$. After stretch, the apical surface was rinsed three times with dye-free DMEM + HEPES and imaged $(\times 10$ objective $)$ using constant exposure, aperture, and fluorescence intensity settings.

The maximum pixel intensity in the background of unstretched-untreated monolayers was measured and used as a threshold to exclude unstained regions. The percentage of each image area ( 3 images/well, 3 wells/animal, from $\geq 3$ animals/group) above the threshold intensity was determined and then divided by the respective value for the unstretched-vehicle control group to calculate the normalized area percentage (nArea) of each image. To test the effect of stretch, animal average nArea values were compared with time-matched unstretched-control values using a one-way ANOVA with post hoc Dunnett's test (95) in JMP. To test the effect of treatment, animal average nArea values were compared with time-matched vehicle controls, as well as unstretched-untreated controls, using a two-way ANOVA with Tukey-Kramer post hoc analysis (95) in JMP.

\section{RESULTS}

RhoA and ROCK activity is reduced with stretch and is dependent on stretch magnitude. We hypothesized that actin cytoskeletal remodeling during rearrangement into PJARs would be preceded or accompanied by an increase in RhoA and ROCK activity. However, quantitative activity assay data refuted our hypothesis: RhoA activity decreased at 10 and $60 \mathrm{~min}$ in monolayers stretched to $37 \% \Delta \mathrm{SA}$ at $0.25 \mathrm{~Hz}$ compared with unstretched monolayers (Fig. 1). Furthermore, ROCK activity decreased at 60 min in monolayers stretched to $25 \% \Delta \mathrm{SA}$ at $0.25 \mathrm{~Hz}$ and at $10 \mathrm{~min}$ in monolayers stretched to $37 \% \Delta \mathrm{SA}$ at $0.25 \mathrm{~Hz}$ but was not changed in monolayers stretched to $12 \% \Delta \mathrm{SA}$ at $0.25 \mathrm{~Hz}$ compared with unstretched monolayers (Fig. 2). Thus RhoA and ROCK activity decreased with stretch, and ROCK activity was sensitive to stretch magnitude and time.

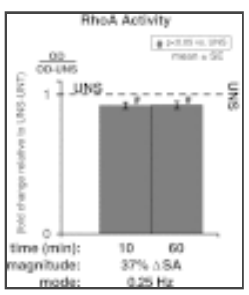

Fig. 1.

RhoA activity is dependent on stretch. RhoA activity was reduced in monolayers stretched to $37 \%$ change in surface area $(\Delta \mathrm{SA})$ at $0.25 \mathrm{~Hz}$ for 10 and $60 \mathrm{~min}$ compared with unstretched (UNS) monolayers. RhoA activity was quantified using an in vitro ... 


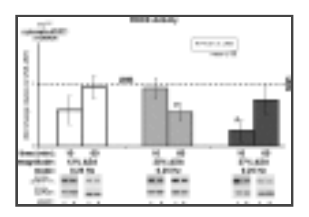

Fig. 2.

Rho kinase (ROCK) activity is dependent on stretch magnitude and time. ROCK activity was reduced in monolayers stretched for $60 \mathrm{~min}$ to $25 \% \Delta \mathrm{SA}$ at $0.25 \mathrm{~Hz}$ and for $10 \mathrm{~min}$ to $37 \% \Delta \mathrm{SA}$ at $0.25 \mathrm{~Hz}$ but not in monolayers stretched to $12 \% \Delta \mathrm{SA} \ldots$

MLC2 phosphorylation is reduced with stretch and is dependent on stretch magnitude. Myosin II has been shown to interact directly with F-actin stress fibers in other cell types (93). We hypothesized that MLC2 would colocalize with PJARs, which exhibit rapidly in stretched type Ilike AEC monolayers (29). We found that dual-phosphorylated ( $\mathrm{Thr}^{18} / \mathrm{Ser}^{19}$ ) MLC2 (Fig. 3A) and total MLC2 (Fig. 3B) colocalize with centrally located F-actin stress fibers in unstretched monolayers (Fig. 3). With 60 min of stretch to $37 \% \Delta \mathrm{SA}$ at $0.25 \mathrm{~Hz}$ (Fig. 3), dualphosphorylated MLC2 redistributed homogeneously throughout the cell, with minor perijunctional staining, comparable to the rapid rearrangement of F-actin into PJARs. Additionally, the overall intensity of dual-phosphorylated MLC2 decreased with stretch. With stretch, total MLC2 localized more centrally within the cell. These data support our hypothesis that MLC2 redistributes and becomes dephosphorylated with stretch in type I-like AEC monolayers.

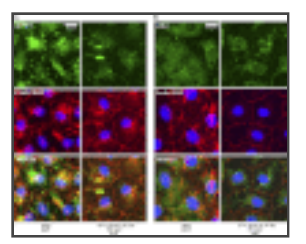

Fig. 3.

Phosphorylated myosin light chain II (MLC2) in stretched and unstretched monolayers. Rat type I-like AEC monolayers before (unstretched) and after stretch to $37 \% \Delta \mathrm{SA}$ at $0.25 \mathrm{~Hz}$ for $60 \mathrm{~min}$ were stained for F-actin with phalloidin (red), nuclei ...

MLC2 can be activated when phosphorylated at $\operatorname{Thr}^{18}$ and $\operatorname{Ser}^{19}$ (40). MLC2 phosphorylation data correlate well with ROCK activity data, showing a decrease in phosphorylation with stretch and stretch magnitude dependence. In monolayers stretched to $25 \% \Delta \mathrm{SA}$ at 0.25 $\mathrm{Hz}, \mathrm{MLC} 2$ dual phosphorylation $\left(\mathrm{Thr}^{18} / \mathrm{Ser}^{19}\right.$ ) was decreased at 1, 10, 30, and 60 min (Fig. 4) and monophosphorylation (Ser $\left.{ }^{19}\right)$ was decreased at $10 \mathrm{~min}(0.534 \pm 0.117)$ compared with unstretched monolayers. Similarly, in monolayers stretched to $37 \% \Delta \mathrm{SA}$ at $0.25 \mathrm{~Hz}$, MLC2 dual phosphorylation was decreased at 1, 10, 30, and 60 min (Fig. 4) compared with unstretched monolayers. Dual-phosphorylated MLC2 was also lower in monolayers stretched to $25 \%$ and $37 \% \Delta \mathrm{SA}$ at $0.25 \mathrm{~Hz}$ than in monolayers stretched to $12 \% \Delta \mathrm{SA}$ at $0.25 \mathrm{~Hz}$ ( Fig. 4) at all times, which was not significantly different from dual-phosphorylated MLC2 in unstretched monolayers. Thus MLC2 phosphorylation $\left(\mathrm{Thr}^{18} / \mathrm{Ser}^{19}\right.$ and $\mathrm{Ser}^{19}$ ) decreased with stretch and was sensitive to stretch magnitude.

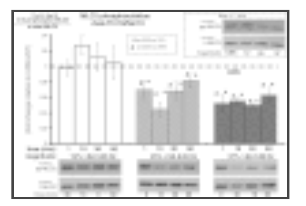

Fig. 4.

MLC2 phosphorylation ( $\mathrm{Thr}^{18} / \mathrm{Ser}^{19}$ ) is dependent on stretch magnitude. Dual phosphorylation of MLC2 is reduced at all times in monolayers stretched to $25 \%$ and $37 \% \Delta \mathrm{SA}$ at $0.25 \mathrm{~Hz}$ compared with unstretched dual-monolayers and monolayers stretched ...

MLC2 activity can be inhibited by phosphorylation at $\operatorname{Ser}^{1}(41,74)$, additionally resulting in reduced myosin affinity for actin filaments. Monolayers stretched for $10 \mathrm{~min}$ to $25 \% \Delta \mathrm{SA}$ at $0.25 \mathrm{~Hz}$ showed no change in phosphorylated (Ser ${ }^{1}$ ) MLC2 compared with unstretched monolayers (not shown). Thus stretch did not affect MLC2 phosphorylation at $\operatorname{Ser}^{1}$ in type I-like AEC monolayers.

MLC2 is phosphorylated with calyculin-A. Hypothesizing that stretch-induced PJAR formation and increased monolayer permeability required decreased MLC2 activation, we used calyculin-A to inhibit MP in stretched monolayers to recover MLC2 phosphorylation to unstretched levels. As hypothesized, MLC2 phosphorylation $\left(\mathrm{Thr}^{18} / \mathrm{Ser}^{19}\right)$ was higher in monolayers pretreated with $10 \mathrm{nM}$ calyculin-A for $60 \mathrm{~min}$ and stretched to $25 \% \Delta \mathrm{SA}$ at $0.25 \mathrm{~Hz}$ for $10 \mathrm{~min}$ (Fig. $5 \mathrm{~A}$ ) than in vehicle control monolayers stretched to the same magnitude and for the same duration (Fig. 5A) and monolayers left unstretched and untreated. Unstretched monolayers pretreated with calyculin-A also show increased MLC2 phosphorylation ( $\mathrm{Thr}^{18} / \mathrm{Ser}^{19}$ ) compared with vehicle control monolayers. Similarly, Bhadriraju et al. (5) used calyculinA in A10 rat aortic smooth muscle cells to increase MLC2 phosphorylation and contractility. Thus the decrease in MLC2 phosphorylation in stretched type I-like AECs is via MP-dependent pathways. 
MLC2 phosphorylation ( $\operatorname{Thr}^{18} / \mathrm{Ser}^{19}$ ) can be activated with calyculin-A, but this did not affect paracellular permeability. $A$ : vehicle control (VC) monolayers stretched to $25 \% \Delta \mathrm{SA}$ at $0.25 \mathrm{~Hz}$ for 10 min show a reduction in phosphorylation $\left(\mathrm{Thr}^{18 / \mathrm{Ser} . .}\right.$

Since we found that phosphorylation of MLC2 decreases with high-magnitude stretch, we hypothesized that inhibition of the MLC2 response with stretch using calyculin-A would attenuate the stretch-induced increase in paracellular permeability. Previously, normalized area stained by the fluorescent tracer BODIPY-ouabain (nArea) was significantly higher in monolayers stretched to $25 \% \Delta \mathrm{SA}$ at $0.25 \mathrm{~Hz}$ for 10 and 60 min than in unstretched-untreated controls (17). However, nArea in monolayers stretched at the same magnitude for the same durations and pretreated with $10 \mathrm{nM}$ calyculin-A for $10 \mathrm{~min}$ was higher at $60 \mathrm{~min}$ than in unstretched-untreated monolayers, and was not different from time-matched stretched-vehicle controls (Fig. 5B). While others have shown that calyculin-A increases epithelial and endothelial permeability $(57,63,78)$, recovering phosphorylation of MLC2 in stretched type I-like AEC monolayers above unstretched levels does not attenuate the stretch-induced increase in paracellular permeability.

PJARs are found in unstretched monolayers with blebbistatin. We initially hypothesized that rapid actin cytoskeletal rearrangement to PJARs would be preceded or accompanied by an increase in ROCK and MLC2 activity in stretched type I-like AEC monolayers. However, our data showed that ROCK activity and MLC2 phosphorylation decreased with stretch. Similarly, inhibition of myosin II ATPase (blebbistatin), ROCK (Y-27632), or MLCK (ML-7) did not prevent rearrangement into PJARs in stretched monolayers (Fig. 6). Interestingly, however, in unstretched monolayers, inhibition of myosin II ATPase (blebbistatin), but not MLCK (ML-7), results in a PJAR-like structure, similar to PJAR rearrangement in stretched-untreated monolayers (Fig. 6). Additionally, in unstretched monolayers, inhibition of ROCK (Y-27632) and myosin II ATPase (blebbistatin) results in a lack of centrally located F-actin stress fibers. Thus stretch-induced PJAR rearrangement was not suppressed with inhibition of myosin II ATPase, ROCK, or MLCK. Furthermore, a PJARlike structure was found in unstretched monolayers with inhibition of myosin II ATPase.

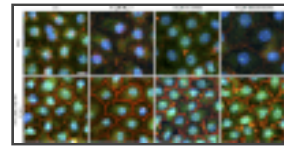

Fig. 6 .

Effect of biaxial stretch and pathway inhibitors on F- and G-actin. Rat type I-like alveolar epithelial cell (AEC) monolayers labeled with phalloidin for F-actin (red), DNase I for G-actin (green), and DAPI for double-stranded DNA (blue) were left unstretched ...

Additionally, we found no significant difference in F- and G-actin content [fold change relative to unstretched vehicle control (means \pm $\mathrm{SE})$ ] of monolayers stretched to $37 \% \Delta \mathrm{SA}$ at $0.25 \mathrm{~Hz}$ for $10 \min (0.79 \pm 0.31$ and $1.31 \pm 0.19$ for $\mathrm{F}$ - and G-actin, respectively) compared with unstretched monolayers $(1.00 \pm 0.34$ and $1.00 \pm 0.19$ for F- and G-actin, respectively) or in unstretched monolayers treated with blebbistatin ( $0.88 \pm 0.38$ and $1.57 \pm 0.23$ for F- and G-actin, respectively) or Y-27632 ( $0.75 \pm 0.44$ and $0.97 \pm 0.26$ for F- and G-actin, respectively) compared with vehicle control. Thus we cannot reject the possibility that PJAR-like structures in type I-like AEC monolayers could be F-actin preserved from depolymerization or rearranged F-actin or both.

MLC2 phosphorylation depends on cell type. Behavior of primary rat type I-like AEC monolayers was compared with behavior of HPAEC monolayers. As previously reported (8), MLC2 phosphorylation $\left(\mathrm{Thr}^{18} / \mathrm{Ser}^{19}\right.$ ) increased in HPAEC monolayers stretched biaxially to $12 \%$ $\triangle \mathrm{SA}$ at $0.25 \mathrm{~Hz}$ for $30 \mathrm{~min}$. However, MLC2 phosphorylation decreased in monolayers stretched to $37 \% \Delta \mathrm{SA}$ at $0.25 \mathrm{~Hz}$ for $30 \mathrm{~min}$ and did not change in monolayers stretched to $25 \% \Delta \mathrm{SA}$ at $0.25 \mathrm{~Hz}$ for $30 \mathrm{~min}$ compared with unstretched HPAEC monolayers (Fig. 7). Phosphorylation was greater in monolayers stretched to $12 \% \Delta \mathrm{SA}$ than in monolayers stretched to $25 \%$ and $37 \% \Delta \mathrm{SA}$. Thus, MLC2 phosphorylation at low-magnitude stretch agrees with previous findings, but like type I-like AECs, phosphorylated MLC2 decreased dramatically at higher-magnitude stretch. 


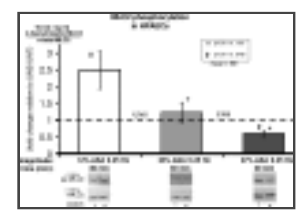

Fig. 7.

MLC2 phosphorylation ( $\mathrm{Thr}^{18} / \mathrm{Ser}^{19}$ ) in human pulmonary artery endothelial cells (HPAECs) is stretch magnitudedependent. Dual phosphorylation of MLC2 increased in monolayers stretched biaxially to $12 \% \Delta \mathrm{SA}$ at $0.25 \mathrm{~Hz}$ for 30 min and decreased in ...

\section{DISCUSSION}

We found that RhoA activity, ROCK activity, and MLC2 phosphorylation decreased with high-magnitude stretch of primary type I-like AEC monolayers. Unlike primary type I-like AECs, HPAEC monolayers stretched for $30 \mathrm{~min}$ to $12 \% \Delta \mathrm{SA}$ at $0.25 \mathrm{~Hz}$ showed increased MLC2 phosphorylation, similar to results published previously by Birukov et al. (8) in HPAECs stretched for 30 min of $18 \%$ cyclic elongation without exposure to thrombin. Furthermore, we demonstrated that MLC2 phosphorylation in HPAECs is stretch magnitudedependent, similar to our findings in type I-like AEC monolayers, with decreased MLC2 phosphorylation at high-magnitude (37\% $\triangle \mathrm{SA})$ stretch. We speculate that high biaxial stretch magnitudes (25\% and $37 \% \Delta \mathrm{SA})$ used in type I-like AEC monolayer models, while physiologically relevant (85), are significantly higher than strain magnitudes typically experienced by endothelial cells utilized in numerous studies that show RhoA, ROCK, and MLC2 activation with stretch. Thus type I-like AEC monolayers respond differently by reducing activation of ROCK and MLC2. We conclude that MLC2 phosphorylation in stretched HPAEC monolayers is significantly different from that in primary AECs at low-magnitude stretch, although the response is similar at high magnitudes. We have shown that rescuing MLC2 phosphorylation during stretch has no effect on monolayer permeability. Finally, unstretched monolayers in which MLC2 activity is inhibited show rearrangement into PJARs.

RhoA and ROCK activity is reduced with stretch and is dependent on stretch magnitude. Previous studies have investigated the ROCK-MLC2 pathway during stretch in other cell types $(1,4,28,71)$. Endothelial cells exposed to elongation show a rapid $(<10$ min) increase in MLC2 phosphorylation via ROCK and MLCK $(8,10,51)$, remodeling of actin to form PJARs $(8,47)$, and Rho activation and peripheral localization (77). RhoA activity was increased in alveolar type II cells isolated from rats exposed to high-tidal-volume mechanical ventilation (28). In unstretched cells, phosphorylation of MLC2 was found to alter actin arrangement rapidly by constriction of PJARs, to increase detergent-soluble (independent of actin) TJ protein content $(65,88,90)$, to increase TJ permeability (68), and to redistribute zonula occludens-1 (ZO-1) and occludin (75). Numerous studies have established the link between stretch and ROCK activation, MLC2 activation, rearrangement into PJARs, and monolayer permeability in endothelial cells (1, 8-10, 47, 77).

In unstretched cells, the ROCK-MLC2 pathway has also been shown to have a major influence on TJ protein coupling and monolayer permeability. For example, in the T84 cell line, constitutively active RhoA redistributed occludin, ZO-1, claudin-1, claudin-2, and junctional adhesion molecule-1, increased detergent solubility of claudin- 1 and claudin-2, and intensified PJARs. In contrast, dominantnegative RhoA abolished PJARs (13) in T84 cells, while ROCK inhibition with Y-27632 decreased PJAR intensity, decreased TER, and colocalized a subpool of ROCK and ZO-1 (90). Furthermore, MP inhibition with calyculin-A prevented infection-induced occludin relocalization and decrease in resistance in T84 cells (78). Latrunculin-A depolymerized actin in Madin-Darby canine kidney cells, resulting in reduction of TER within 5 min, internalization of occludin, and abolishment of PJARs (76). In Caco-2 cells, inactivation of the $\mathrm{Na}^{+}$-glucose cotransporter SGLT1 resulted in increased TER, which was reversible by MLCK inhibition. SGLT1 activation increased MLC2 phosphorylation and was reversible by MLCK inhibition via ML-9 (89).

In summary, these studies in unstretched cells show parallel changes and associations between PJAR morphology, TJ protein distribution, and permeability modulated by Rho, MLCK, ROCK, and MLC2. Previously, we reported stretch magnitude- and frequency-dependent PJAR formation (29) and a stretch-induced increase in paracellular permeability (17, 18) in type I-like AEC monolayers. We hypothesized that RhoA and ROCK were activated with stretch and that the stretch-induced increase in monolayer permeability could be attenuated with pharmacological inhibition of ROCK. Counter to our hypothesis, we found that RhoA activity and downstream ROCK activity are significantly decreased with high-magnitude stretch of type I-like AEC monolayers, revealing that other pathways may be responsible for rearrangement into PJARs at high-magnitude stretch. Additionally, while we found a decrease in RhoA activity at 10 and $60 \mathrm{~min}$ of stretch to $37 \% \triangle \mathrm{SA}$ at $0.25 \mathrm{~Hz}$, ROCK activity was decreased at only $10 \mathrm{~min}$. We speculate that other pathway intermediates, including Ras and ERK (73), may be involved in the signaling between RhoA and ROCK in stretched type I-like AEC monolayers.

MLC2 phosphorylation is reduced with stretch and is dependent on stretch magnitude. MLC2 phosphorylation data correlated well with ROCK activity data, showing a stretch magnitude-dependent decrease in MLC2 phosphorylation $\left(\mathrm{Thr}^{18} / \mathrm{Ser}^{19}\right)$ with high-magnitude stretch $(25 \%$ 
and 37\% $\triangle \mathrm{SA})$ but no change at low-magnitude stretch (12\% $\triangle \mathrm{SA})$. While MLC2 phosphorylation was decreased at all times in monolayers stretched to $25 \%$ and $37 \% \Delta \mathrm{SA}$ at $0.25 \mathrm{~Hz}$, ROCK activity was decreased only at 60 min of stretch to $25 \% \Delta \mathrm{SA}$ and $10 \mathrm{~min}$ of stretch to $37 \% \Delta \mathrm{SA}$, evidence that additional pathways, including MLCK (45) and MP (49, 72), may contribute to the phosphorylation state of MLC2 in stretched type I-like AEC monolayers. MLC2 monophosphorylation at $\mathrm{Ser}^{19}$, a site shown to have higher affinity for ROCK-mediated phosphorylation (40, 83), similarly decreased phosphorylation in stretched monolayers. Similarly, Mizutani et al. (62) demonstrated a decrease in MLC2 phosphorylation $\left(\mathrm{Thr}^{18} / \mathrm{Ser}^{19}\right)$ in NIH-3T3 cells stretched for $1-2 \mathrm{~h}$ uniaxially at $10 \%$. Thus MLC2 phosphorylation in type I-like AEC monolayers subjected to high-magnitude stretch decreased; we speculate that this results in reduced MLC2 activity and contractile force. Additionally, a minor amount of dual-phosphorylated MLC2 was found to colocalize with F-actin in stretched monolayers. Others have shown MLC2 colocalization with F-actin in other cell types (7, 93), and we speculate that MLC2 anchoring to the actin cytoskeleton is necessary for force generation. Together with previous data showing a rapid increase in actin rearrangement during stretch (29) and minor MLC2 colocalization with stretch-induced PJARs, we speculate that monolayer tension may diminish in stretched type I-like AEC monolayers, previously demonstrated in other stretched cell types (15, 53, 84).

PJAR is found in unstretched monolayers with blebbistatin. Stretch-induced rearrangement into PJARs was unaffected by MLCK inhibition by ML-7, ROCK inhibition by Y-27632, and MLC2 activity inhibition by blebbistatin under high-magnitude stretch conditions. Interestingly, a PJAR-like structure was found in unstretched monolayers treated with the MLC2 activity inhibitor, but not with the MLCK inhibitor. It is not known if these PJAR-like structures formed because of the presence of the inhibitor or if peripherally located F-actin was preserved from inhibitor-induced depolymerization. Additionally, unstretched monolayers treated with Y-27632 or blebbistatin lack centrally located F-actin stress fibers found in unstretched vehicle control monolayers. Bhadriraju et al. (6) demonstrated reduced ROCK activity and MLC2 phosphorylation that could not be rescued by constitutively active RhoA in endothelial cells with diminished actin-mediated extracellular matrix adhesion. Additionally, treatment with blebbistatin to reduce cellular tension resulted in decreased focal adhesions, as well as reduced ROCK and MLC2 activity (6). Others have shown that injection of RhoA induces assembly of stress fibers and focal contacts $(4,71)$. Furthermore, endothelial cells treated with sphingosine 1-phosphate exhibit a thick cortical actin ring and enhanced barrier and adhesion properties (81). Taken together with our data showing decreased ROCK and MLC2 activity with stretch and reorganization into PJARs in unstretched monolayers with inhibition of myosin II ATPase, these previous studies lead us to speculate that type I-like AEC monolayer adhesion to the extracellular matrix may be reduced with high-magnitude biaxial stretch.

Summary. We have demonstrated that RhoA activity, ROCK activity, and MLC2 phosphorylation decrease with high-magnitude stretch of primary type I-like AEC and HPAEC monolayers. This inactivation is stretch-magnitude-dependent and occurs via the MP pathway in type I-like AECs. We have shown that rescuing MLC2 phosphorylation during stretch has no effect on monolayer permeability. We have demonstrated that, in unstretched type I-like AEC monolayers, the actin cytoskeleton remodels to PJARs in the presence of the myosin II ATPase inhibitor blebbistatin. Future studies should investigate pathways involved in actin remodeling and their effect on paracellular permeability during stretch in order to explore opportunities to prevent ventilator-induced lung injury.

\section{GRANTS}

This study was supported by National Heart, Lung, and Blood Institute Grant R01-HL-057204 (S. S. Margulies) and the University of Pennsylvania Ashton Fellowship Program (B. C. DiPaolo).

\section{DISCLOSURES}

No conflicts of interest, financial or otherwise, are declared by the authors.

\section{Article information}

Am J Physiol Lung Cell Mol Physiol. 2012 May 15; 302(10): L992-L1002.

Published online 2012 Jan 27. doi: 10.1152/ajplung.00175.2011

Brian C. DiPaolo and Susan S. Margulies ${ }^{\mathbb{X}}$

Department of Bioengineering, University of Pennsylvania, Philadelphia, Pennsylvania

$\bigotimes_{\text {Corresponding author. }}$ 
Address for reprint requests and other correspondence: S. S. Margulies, Dept. of Bioengineering, Univ. of Pennsylvania, 240 Skirkanich Hall, 210 South 33 rd St., Philadelphia, PA 19104-6321 (e-mail: margulies@seas.upenn.edu).

Received 2011 Jun 3; Accepted 2012 Jan 24.

Copyright @ 2012 the American Physiological Society

This article has been cited by other articles in PMC.

Articles from American Journal of Physiology - Lung Cellular and Molecular Physiology are provided here courtesy of American Physiological Society

\section{REFERENCES}

1. Albinsson S, Nordstrom I, Hellstrand P. Stretch of the vascular wall induces smooth muscle differentiation by promoting actin polymerization. J Biol Chem 279: 34849-34855, 2004 [PubMed]

2. Amano M, Ito M, Kimura K, Fukata Y, Chihara K, Nakano T, Matsuura Y, Kaibuchi K. Phosphorylation and activation of myosin by Rhoassociated kinase (Rho-kinase). J Biol Chem 271: 20246-20249, 1996 [PubMed]

3. An SS, Fabry B, Mellema M, Bursac P, Gerthoffer WT, Kayyali US, Gaestel M, Shore SA, Fredberg JJ. Role of heat shock protein 27 in cytoskeletal remodeling of the airway smooth muscle cell. J Appl Physiol 96: 1701-1713, 2004 [PubMed]

4. Aspenstrom P. Effectors for the Rho GTPases. Curr Opin Cell Biol 11: 95-102, 1999 [PubMed]

5. Bhadriraju K, Elliott JT, Nguyen M, Plant AL. Quantifying myosin light chain phosphorylation in single adherent cells with automated fluorescence microscopy. BMC Cell Biol 8: 43, 2007 [PMC free article] [PubMed]

6. Bhadriraju K, Yang M, Alom Ruiz S, Pirone D, Tan J, Chen CS. Activation of ROCK by RhoA is regulated by cell adhesion, shape, and cytoskeletal tension. Exp Cell Res 313: 3616-3623, 2007 [PMC free article] [PubMed]

7. Birukov KG, Birukova AA, Dudek SM, Verin AD, Crow MT, Zhan X, DePaola N, Garcia JG. Shear stress-mediated cytoskeletal remodeling and cortactin translocation in pulmonary endothelial cells. Am J Respir Cell Mol Biol 26: 453-464, 2002 [PubMed]

8. Birukov KG, Jacobson JR, Flores AA, Ye SQ, Birukova AA, Verin AD, Garcia JG. Magnitude-dependent regulation of pulmonary endothelial cell barrier function by cyclic stretch. Am J Physiol Lung Cell Mol Physiol 285: L785-L797, 2003 [PubMed]

9. Birukova AA, Fu P, Xing J, Cokic I, Birukov KG. Lung endothelial barrier protection by iloprost in the 2-hit models of ventilator-induced lung injury (VILI) involves inhibition of Rho signaling. Transl Res 155: 44-54, 2010 [PMC free article] [PubMed]

10. Birukova AA, Rios A, Birukov KG. Long-term cyclic stretch controls pulmonary endothelial permeability at translational and post-translational levels. Exp Cell Res 314: 3466-3477, 2008 [PMC free article] [PubMed]

11. Birukova AA, Smurova K, Birukov KG, Kaibuchi K, Garcia JG, Verin AD. Role of Rho GTPases in thrombin-induced lung vascular endothelial cells barrier dysfunction. Microvasc Res 67: 64-77, 2004 [PubMed]

12. Borok Z, Danto SI, Zabski SM, Crandall ED. Defined medium for primary culture de novo of adult rat alveolar epithelial cells. In Vitro Cell Dev Biol Anim 30A: 99-104, 1994 [PubMed]

13. Bruewer M, Hopkins AM, Hobert ME, Nusrat A, Madara JL. RhoA, Rac1, and Cdc42 exert distinct effects on epithelial barrier via selective structural and biochemical modulation of junctional proteins and F-actin. Am J Physiol Cell Physiol 287: C327-C335, 2004 [PubMed]

14. Bursac P, Fabry B, Trepat X, Lenormand G, Butler JP, Wang N, Fredberg JJ, An SS. Cytoskeleton dynamics: fluctuations within the network. Biochem Biophys Res Commun 355: 324-330, 2007 [PMC free article] [PubMed]

15. Bursac P, Lenormand G, Fabry B, Oliver M, Weitz DA, Viasnoff V, Butler JP, Fredberg JJ. Cytoskeletal remodelling and slow dynamics in the living cell. Nat Mater 4: 557-561, 2005 [PubMed]

16. Cavanaugh KJ, Cohen TS, Margulies SS. Stretch increases alveolar epithelial permeability to uncharged micromolecules. Am J Physiol Cell Physiol 290: C1179-C1188, 2006 [PMC free article] [PubMed] 
17. Cavanaugh KJ, Jr, Margulies SS. Measurement of stretch-induced loss of alveolar epithelial barrier integrity with a novel in vitro method. Am J Physiol Cell Physiol 283: C1801-C1808, 2002 [PubMed]

18. Cavanaugh KJ, Jr, Oswari J, Margulies SS. Role of stretch on tight junction structure in alveolar epithelial cells. Am J Respir Cell Mol Biol 25: 584-591, 2001 [PubMed]

19. Cheek JM, Evans MJ, Crandall ED. Type I cell-like morphology in tight alveolar epithelial monolayers. Exp Cell Res 184: 375-387, 1989 [PubMed]

20. Chen X, Pavlish K, Benoit JN. Myosin phosphorylation triggers actin polymerization in vascular smooth muscle. Am J Physiol Heart Circ Physiol 295: H2172-H2177, 2008 [PMC free article] [PubMed]

21. Chicurel ME, Chen CS, Ingber DE. Cellular control lies in the balance of forces. Curr Opin Cell Biol 10: 232-239, 1998 [PubMed]

22. Chihara K, Amano M, Nakamura N, Yano T, Shibata M, Tokui T, Ichikawa H, Ikebe R, Ikebe M, Kaibuchi K. Cytoskeletal rearrangements and transcriptional activation of c-fos serum response element by Rho-kinase. J Biol Chem 272: 25121-25127, 1997 [PubMed]

23. Cohen P, Klumpp S, Schelling DL. An improved procedure for identifying and quantitating protein phosphatases in mammalian tissues. FEBS Lett 250: 596-600, 1989 [PubMed]

24. Cohen TS, Cavanaugh KJ, Margulies SS. Frequency and peak stretch magnitude affect alveolar epithelial permeability. Eur Respir J 32: 854861,2008 [PubMed]

25. Collins NT, Cummins PM, Colgan OC, Ferguson G, Birney YA, Murphy RP, Meade G, Cahill PA. Cyclic strain-mediated regulation of vascular endothelial occludin and ZO-1: influence on intercellular tight junction assembly and function. Arterioscler Thromb Vasc Biol 26: 62-68, 2006 [PubMed]

26. Craig R, Smith R, Kendrick-Jones J. Light-chain phosphorylation controls the conformation of vertebrate non-muscle and smooth muscle myosin molecules. Nature 302: 436-439, 1983 [PubMed]

27. Danto SI, Zabski SM, Crandall ED. Reactivity of alveolar epithelial cells in primary culture with type I cell monoclonal antibodies. Am J Respir Cell Mol Biol 6: 296-306, 1992 [PubMed]

28. Desai LP, Sinclair SE, Chapman KE, Hassid A, Waters CM. High tidal volume mechanical ventilation with hyperoxia alters alveolar type II cell adhesion. Am J Physiol Lung Cell Mol Physiol 293: L769-L778, 2007 [PubMed]

29. DiPaolo BC, Lenormand G, Fredberg JJ, Margulies SS. Stretch magnitude and frequency-dependent actin cytoskeleton remodeling in alveolar epithelia. Am J Physiol Cell Physiol 299: C345-C353, 2010 [PMC free article] [PubMed]

30. Dittmer A, Dittmer J. $\beta$-Actin is not a reliable loading control in Western blot analysis. Electrophoresis 27: 2844-2845, 2006 [PubMed]

31. Dobbs LG, Gonzalez R, Williams MC. An improved method for isolating type II cells in high yield and purity. Am Rev Respir Dis 134: 141145,1986 [PubMed]

32. Eddinger TJ, Meer DP. Myosin II isoforms in smooth muscle: heterogeneity and function. Am J Physiol Cell Physiol 293: C493-C508, 2007 [ PubMed]

33. Egan EA. Lung inflation, lung solute permeability, and alveolar edema. J Appl Physiol 53: 121-125, 1982 [PubMed]

34. Fanning AS, Jameson BJ, Jesaitis LA, Anderson JM. The tight junction protein ZO-1 establishes a link between the transmembrane protein occludin and the actin cytoskeleton. J Biol Chem 273: 29745-29753, 1998 [PubMed]

35. Feng J, Ito M, Ichikawa K, Isaka N, Nishikawa M, Hartshorne DJ, Nakano T. Inhibitory phosphorylation site for Rho-associated kinase on smooth muscle myosin phosphatase. J Biol Chem 274: 37385-37390, 1999 [PubMed]

36. Fujiwara K, Pollard TD. Fluorescent antibody localization of myosin in the cytoplasm, cleavage furrow, and mitotic spindle of human cells. J Cell Biol 71: 848-875, 1976 [PMC free article] [PubMed]

37. Gassmann M, Grenacher B, Rohde B, Vogel J. Quantifying Western blots: pitfalls of densitometry. Electrophoresis 30: 1845-1855, 2009 
38. Grant JW, Taubman MB, Church SL, Johnson RL, Nadal-Ginard B. Mammalian nonsarcomeric myosin regulatory light chains are encoded by two differentially regulated and linked genes. J Cell Biol 111: 1127-1135, 1990 [PMC free article] [PubMed]

39. Hecht G, Pestic L, Nikcevic G, Koutsouris A, Tripuraneni J, Lorimer DD, Nowak G, Guerriero V, Jr, Elson EL, Lanerolle PD. Expression of the catalytic domain of myosin light chain kinase increases paracellular permeability. Am J Physiol Cell Physiol 271: C1678-C1684, 1996 [PubMed]

40. Ikebe M, Hartshorne DJ. Phosphorylation of smooth muscle myosin at two distinct sites by myosin light chain kinase. J Biol Chem 260: 10027-10031, 1985 [PubMed]

41. Ikebe M, Hartshorne DJ, Elzinga M. Phosphorylation of the 20,000-dalton light chain of smooth muscle myosin by the calcium-activated, phospholipid-dependent protein kinase. Phosphorylation sites and effects of phosphorylation. J Biol Chem 262: 9569-9573, 1987 [PubMed]

42. Ishihara H, Martin BL, Brautigan DL, Karaki H, Ozaki H, Kato Y, Fusetani N, Watabe S, Hashimoto K, Uemura D, et al. Calyculin A and okadaic acid: inhibitors of protein phosphatase activity. Biochem Biophys Res Commun 159: 871-877, 1989 [PubMed]

43. Ishizaki T, Maekawa M, Fujisawa K, Okawa K, Iwamatsu A, Fujita A, Watanabe N, Saito Y, Kakizuka A, Morii N, Narumiya S. The small GTP-binding protein Rho binds to and activates a $160 \mathrm{kDa}$ Ser/Thr protein kinase homologous to myotonic dystrophy kinase. EMBO J 15: 18851893, 1996 [PMC free article] [PubMed]

44. Jewell EA, Shamraj OI, Lingrel JB. Isoforms of the $\alpha$-subunit of Na,K-ATPase and their significance. Acta Physiol Scand Suppl 607: 161-169, 1992 [PubMed]

45. Kamm KE, Stull JT. Dedicated myosin light chain kinases with diverse cellular functions. J Biol Chem 276: 4527-4530, 2001 [PubMed]

46. Kano Y, Katoh K, Masuda M, Fujiwara K. Macromolecular composition of stress fiber-plasma membrane attachment sites in endothelial cells in situ. Circ Res 79: 1000-1006, 1996 [PubMed]

47. Kaunas R, Nguyen P, Usami S, Chien S. Cooperative effects of Rho and mechanical stretch on stress fiber organization. Proc Natl Acad Sci USA 102: 15895-15900, 2005 [PMC free article] [PubMed]

48. Kim KJ, Crandall ED. Effects of lung inflation on alveolar epithelial solute and water transport properties. J Appl Physiol 52: 1498-1505, 1982 [PubMed]

49. Kimura K, Ito M, Amano M, Chihara K, Fukata Y, Nakafuku M, Yamamori B, Feng J, Nakano T, Okawa K, Iwamatsu A, Kaibuchi K. Regulation of myosin phosphatase by Rho and Rho-associated kinase (Rho-kinase). Science 273: 245-248, 1996 [PubMed]

50. Klemke RL, Cai S, Giannini AL, Gallagher PJ, de Lanerolle P, Cheresh DA. Regulation of cell motility by mitogen-activated protein kinase. J Cell Biol 137: 481-492, 1997 [PMC free article] [PubMed]

51. Kockskamper J, Khafaga M, Grimm M, Elgner A, Walther S, Kockskamper A, von Lewinski D, Post H, Grossmann M, Dorge H, Gottlieb PA, Sachs F, Eschenhagen T, Schondube FA, Pieske B. Angiotensin II and myosin light-chain phosphorylation contribute to the stretch-induced slow force response in human atrial myocardium. Cardiovasc Res 79: 642-651, 2008 [PMC free article] [PubMed]

52. Krarup T, Jakobsen LD, Jensen BS, Hoffmann EK. $\mathrm{Na}^{+}-\mathrm{K}^{+}-2 \mathrm{Cl}^{-}$cotransport in Ehrlich cells: regulation by protein phosphatases and kinases. Am J Physiol Cell Physiol 275: C239-C250, 1998 [PubMed]

53. Krishnan R, Park CY, Lin YC, Mead J, Jaspers RT, Trepat X, Lenormand G, Tambe D, Smolensky AV, Knoll AH, Butler JP, Fredberg JJ. Reinforcement versus fluidization in cytoskeletal mechanoresponsiveness. PLos One 4: e5486, 2009 [PMC free article] [PubMed]

54. Li Z, Chang Z, Chiao LJ, Kang Y, Xia Q, Zhu C, Fleming JB, Evans DB, Chiao PJ. TrkBT1 induces liver metastasis of pancreatic cancer cells by sequestering Rho GDP dissociation inhibitor and promoting RhoA activation. Cancer Res 69: 7851-7859, 2009 [PMC free article] [PubMed]

55. Liebler JM, Borok Z, Li X, Zhou B, Sandoval AJ, Kim KJ, Crandall ED. Alveolar epithelial type I cells express $\beta_{2}$-adrenergic receptors and Gprotein receptor kinase 2. J Histochem Cytochem 52: 759-767, 2004 [PubMed] 
56. Liu WF, Nelson CM, Tan JL, Chen CS. Cadherins, RhoA, and Rac1 are differentially required for stretch-mediated proliferation in endothelial versus smooth muscle cells. Circ Res 101: e44-e52, 2007 [PubMed]

57. Lum H, Podolski JL, Gurnack ME, Schulz IT, Huang F, Holian O. Protein phosphatase 2B inhibitor potentiates endothelial PKC activity and barrier dysfunction. Am J Physiol Lung Cell Mol Physiol 281: L546-L555, 2001 [PubMed]

58. Madara JL. Intestinal absorptive cell tight junctions are linked to cytoskeleton. Am J Physiol Cell Physiol 253: C171-C175, 1987 [PubMed]

59. Madara JL, Pappenheimer JR. Structural basis for physiological regulation of paracellular pathways in intestinal epithelia. J Membr Biol 100: 149-164, 1987 [PubMed]

60. Messer NG, Kendrick-Jones J. Molecular cloning and sequencing of the chicken smooth muscle myosin regulatory light chain. FEBS Lett 234: 49-52, 1988 [PubMed]

61. Mizutani T, Haga H, Koyama Y, Takahashi M, Kawabata K. Diphosphorylation of the myosin regulatory light chain enhances the tension acting on stress fibers in fibroblasts. J Cell Physiol 209: 726-731, 2006 [PubMed]

62. Mizutani T, Kawabata K, Koyama Y, Takahashi M, Haga H. Regulation of cellular contractile force in response to mechanical stretch by diphosphorylation of myosin regulatory light chain via RhoA signaling cascade. Cell Motil Cytoskeleton 66: 389-397, 2009 [PubMed]

63. Mucha DR, Myers CL, Schaeffer RC., Jr Endothelial contraction and monolayer hyperpermeability are regulated by Src kinase. Am J Physiol Heart Circ Physiol 284: H994-H1002, 2003 [PubMed]

64. Nusrat A, Giry M, Turner JR, Colgan SP, Parkos CA, Carnes D, Lemichez E, Boquet P, Madara JL. Rho protein regulates tight junctions and perijunctional actin organization in polarized epithelia. Proc Natl Acad Sci USA 92: 10629-10633, 1995 [PMC free article] [PubMed]

65. Nusrat A, Turner JR, Madara JL. Molecular physiology and pathophysiology of tight junctions. IV. Regulation of tight junctions by extracellular stimuli: nutrients, cytokines, and immune cells. Am J Physiol Gastrointest Liver Physiol 279: G851-G857, 2000 [PubMed]

66. Ohashi K, Nagata K, Maekawa M, Ishizaki T, Narumiya S, Mizuno K. Rho-associated kinase ROCK activates LIM-kinase 1 by phosphorylation at threonine 508 within the activation loop. J Biol Chem 275: 3577-3582, 2000 [PubMed]

67. Oswari J, Matthay MA, Margulies SS. Keratinocyte growth factor reduces alveolar epithelial susceptibility to in vitro mechanical deformation. Am J Physiol Lung Cell Mol Physiol 281: L1068-L1077, 2001 [PubMed]

68. Petrache I, Verin AD, Crow MT, Birukova A, Liu F, Garcia JG. Differential effect of MLC kinase in TNF- $\alpha$-induced endothelial cell apoptosis and barrier dysfunction. Am J Physiol Lung Cell Mol Physiol 280: L1168-L1178, 2001 [PubMed]

69. Poley RN, Dosier CR, Speich JE, Miner AS, Ratz PH. Stimulated calcium entry and constitutive RhoA kinase activity cause stretch-induced detrusor contraction. Eur J Pharmacol 599: 137-145, 2008 [PMC free article] [PubMed]

70. Qiao R, Zhou B, Liebler JM, Li X, Crandall ED, Borok Z. Identification of three genes of known function expressed by alveolar epithelial type I cells. Am J Respir Cell Mol Biol 29: 98-105, 2003 [PubMed]

71. Ridley AJ. Rho family proteins: coordinating cell responses. Trends Cell Biol 11: 471-477, 2001 [PubMed]

72. Riento K, Ridley AJ. Rocks: multifunctional kinases in cell behaviour. Nat Rev Mol Cell Biol 4: 446-456, 2003 [PubMed]

73. Sahai E, Olson MF, Marshall CJ. Cross-talk between Ras and Rho signalling pathways in transformation favours proliferation and increased motility. EMBO J 20: 755-766, 2001 [PMC free article] [PubMed]

74. Satterwhite LL, Lohka MJ, Wilson KL, Scherson TY, Cisek LJ, Corden JL, Pollard TD. Phosphorylation of myosin-II regulatory light chain by cyclin-p34cdc2: a mechanism for the timing of cytokinesis. J Cell Biol 118: 595-605, 1992 [PMC free article] [PubMed]

75. Shen L, Black ED, Witkowski ED, Lencer WI, Guerriero V, Schneeberger EE, Turner JR. Myosin light chain phosphorylation regulates barrier function by remodeling tight junction structure. J Cell Sci 119: 2095-2106, 2006 [PubMed]

76. Shen L, Turner JR. Actin depolymerization disrupts tight junctions via caveolae-mediated endocytosis. Mol Biol Cell 16: 3919-3936, 2005 [PMC free article] [PubMed] 
77. Shikata Y, Rios A, Kawkitinarong K, DePaola N, Garcia JG, Birukov KG. Differential effects of shear stress and cyclic stretch on focal adhesion remodeling, site-specific FAK phosphorylation, and small GTPases in human lung endothelial cells. Exp Cell Res 304: 40-49, 2005 [PubMed]

78. Simonovic I, Rosenberg J, Koutsouris A, Hecht G. Enteropathogenic Escherichia coli dephosphorylates and dissociates occludin from intestinal epithelial tight junctions. Cell Microbiol 2: 305-315, 2000 [PubMed]

79. Somlyo AP, Somlyo AV. $\mathrm{Ca}^{2+}$ sensitivity of smooth muscle and nonmuscle myosin II: modulated by G proteins, kinases, and myosin phosphatase. Physiol Rev 83: 1325-1358, 2003 [PubMed]

80. Sumi T, Matsumoto K, Nakamura T. Specific activation of LIM kinase 2 via phosphorylation of threonine 505 by ROCK, a Rho-dependent protein kinase. J Biol Chem 276: 670-676, 2001 [PubMed]

81. Sun X, Shikata Y, Wang L, Ohmori K, Watanabe N, Wada J, Shikata K, Birukov KG, Makino H, Jacobson JR, Dudek SM, Garcia JG. Enhanced interaction between focal adhesion and adherens junction proteins: involvement in sphingosine 1-phosphate-induced endothelial barrier enhancement. Microvasc Res 77: 304-313, 2009 [PMC free article] [PubMed]

82. Sweadner KJ. Isozymes of the $\mathrm{Na}^{+} / \mathrm{K}^{+}$-ATPase. Biochim Biophys Acta 988: 185-220, 1989 [PubMed]

83. Totsukawa G, Yamakita Y, Yamashiro S, Hartshorne DJ, Sasaki Y, Matsumura F. Distinct roles of ROCK (Rho-kinase) and MLCK in spatial regulation of MLC phosphorylation for assembly of stress fibers and focal adhesions in 3T3 fibroblasts. J Cell Biol 150: 797-806, 2000 [PMC free article] [PubMed]

84. Trepat X, Deng L, An SS, Navajas D, Tschumperlin DJ, Gerthoffer WT, Butler JP, Fredberg JJ. Universal physical responses to stretch in the living cell. Nature 447: 592-595, 2007 [PMC free article] [PubMed]

85. Tschumperlin DJ, Margulies SS. Equibiaxial deformation-induced injury of alveolar epithelial cells in vitro. Am J Physiol Lung Cell Mol Physiol 275: L1173-L1183, 1998 [PubMed]

86. Tschumperlin DJ, Oswari J, Margulies AS. Deformation-induced injury of alveolar epithelial cells. Effect of frequency, duration, and amplitude. Am J Respir Crit Care Med 162: 357-362, 2000 [PubMed]

87. Turner JR. "Putting the squeeze" on the tight junction: understanding cytoskeletal regulation. Semin Cell Dev Biol 11: 301-308, 2000 [PubMed]

88. Turner JR, Angle JM, Black ED, Joyal JL, Sacks DB, Madara JL. PKC-dependent regulation of transepithelial resistance: roles of MLC and MLC kinase. Am J Physiol Cell Physiol 277: C554-C562, 1999 [PubMed]

89. Turner JR, Rill BK, Carlson SL, Carnes D, Kerner R, Mrsny RJ, Madara JL. Physiological regulation of epithelial tight junctions is associated with myosin light-chain phosphorylation. Am J Physiol Cell Physiol 273: C1378-C1385, 1997 [PubMed]

90. Walsh SV, Hopkins AM, Chen J, Narumiya S, Parkos CA, Nusrat A. Rho kinase regulates tight junction function and is necessary for tight junction assembly in polarized intestinal epithelia. Gastroenterology 121: 566-579, 2001 [PubMed]

91. Wang JH, Goldschmidt-Clermont P, Wille J, Yin FC. Specificity of endothelial cell reorientation in response to cyclic mechanical stretching. J Biomech 34: 1563-1572, 2001 [PubMed]

92. Waters CM, Ridge KM, Sunio G, Venetsanou K, Sznajder JI. Mechanical stretching of alveolar epithelial cells increases $\mathrm{Na}^{+}-\mathrm{K}^{+}-\mathrm{ATPase}^{-}$ activity. J Appl Physiol 87: 715-721, 1999 [PubMed]

93. White GE, Gimbrone MA, Jr, Fujiwara K. Factors influencing the expression of stress fibers in vascular endothelial cells in situ. J Cell Biol 97: 416-424, 1983 [PMC free article] [PubMed]

94. Yanase M, Ikeda H, Ogata I, Matsui A, Noiri E, Tomiya T, Arai M, Inoue Y, Tejima K, Nagashima K, Nishikawa T, Shibata M, Ikebe M, Rojkind M, Fujiwara K. Functional diversity between Rho-kinase- and MLCK-mediated cytoskeletal actions in a myofibroblast-like hepatic stellate cell line. Biochem Biophys Res Commun 305: 223-228, 2003 [PubMed]

95. Zar H. Biostatistical Analysis. Upper Saddle River, NJ: Prentice Hall, 1999 
96. Zhang M, Rao PV. Blebbistatin, a novel inhibitor of myosin II ATPase activity, increases aqueous humor outflow facility in perfused enucleated porcine eyes. Invest Ophthalmol Vis Sci 46: 4130-4138, 2005 [PubMed] 